\title{
LA HISTORIA NATURAL Y MORAL EN LA OBRA DE A. J. CAVANILLES
}

POR

\author{
FERNANDO MONGE MARTÍNEZ
}

\begin{abstract}
Pretendemos considerar aquí aquellos aspectos que pudieran ser herederos de la Historia Natural y Moral que se desarrolló fundamentalmente en los siglos XVI y XVII y, hasta qué punto la ciencia natural española de la Ilustración entronca con su propia tradición cultural. Para ello analizaremos la obra del abate Antonio José Cavanilles en conjunto, centrándonos particularmente en la revista Anales de.Historia Natural (más tarde titulados Anales de Ciencias Naturales) y su libro más conocido Observaciones sobre la Historia Natural, geografía, agricultura, población y frutos del Reyno de Valencia (1795-97) (1).
\end{abstract}

\section{ESBOZO BIOGRÁFICO}

La vida de Antonio José Cavanilles (Valencia 1745-Madrid 1804) es bien conocida y apenas requiere atención especial. Son numerosas las publicaciones de toda índole, tanto especializada como si no, en los que se le dedica algún espacio y atención. Sin embargo es importante destacar algunos aspectos biográficos

SIGLAS UTILIZADAS:

ACN: Anales de Ciencias Naturales, Madrid.

AHN: Anales de Historia Natural, Madrid.

(1) Conste aquí mi agradecimiento al Dr. Fermín del Pino, director del Seminario sobre Historia Natural y Moral (Madrid 1986) y de mi tesis doctoral, dado que, gracias a sus recomendaciones y sugerencias, ha conseguido que diera fin a este trabajo. Asimismo quiero expresar mi agradecimiento a todo el personal de la biblioteca del Real Jardín Botánico de Madrid, su ayuda y facilidades son las que hacen cualquier investigación agradable y posible. Este artículo formó parte de dicho Seminario. 
antes de introducirnos en su obra. Antonio Mestre (2) considera tres etapas claves en su vida: los años de formación (1745-77), su residencia en París (1777-89) y sus últimos años en España (1789. 1804). En cada una de estas tres fases nos encontramos a un Cavanilles distinto, aunque siempre inquieto y deseoso de indagar la verdad. Durante sus primeros años no sólo estudió humanidades y teología (1762-66) en los colegios jesuitas de su ciudad natal y de Gandía sino que, además entabló contacto con Juan Bautista Muñoz (3), Francisco Pérez Bayer y los hermanos Mayans, enseñó filosofía y matemáticas, primero en la Universidad de Valencia a la que opositó sin éxito en 1770 y luego como titular de la cátedra de filosofía del Colegio de San Fulgencio (1776-77). En 1777, una vez ordenado sacerdote en Oviedo (1772) y después de haber ejercido como instructor del hijo del oidor de la Audiencia de Valencia, Teodoro Caro Briones, acepta el cargo de perceptor del hijo del duque del Infantado. Cavanilles se trasladará a París tras ser nombrado el duque embajador de España en Francia, asiste allí a las clases, junto con su pupilo, de Historia Natural impartidas por Jean Darcet, y de física por Maturin Jacobe Brisson. Estudia botánica junto a personajes de la talla de Antonio Lorenzo de Jussieu y de Lamarck, con quien mantuvo relación hasta el final de sus días. Asimismo entabla amistad con José Viera y Clavijo (4) y con Juan Antonio Mayans. Y en 1784 su nombre se hace conocido gracias a la publicación de una réplica, en defensa de la ciencia española, al artículo de Masson de Morvilliers sobre España, publicado en la Nueva Enciclopedia (5). Un año más tarde comienzan a aparecer sus monografías o disertaciones botánicas (6). La primera de ellas, aparecida en París en 1785, Dissertatio botanica de Sida et de quibusdam plantis quae cum illa affinitatem habent, merecerá el honor de ser incluida en el Ensayo de una biblioteca española de los mejores escritores del Reynado de Carlos III, de J. Sempere y

(2) Antonio Mestre, "Cavanilles, entre la Ilustración y la Política", y Cavanilles. Naturalista de la Ilustración, 1745-1904. Real Jardín Botánico. Madrid, 1983.

(3) Juan Bautista MuÑoz escribió la Historia del Nuevo Mundo. Gracias a su amistad con él tiene acceso Cavanilles a importantes obras de historia natural y moral americanas transcritas o aún los originales.

(4) Cartas a José Viera y Clavijo. Santa Cruz de Tenerife, Excmo. Cabildo Insular de Tenerife, 1981.

(5) Todas las referencias y citas que hagamos de las obras de Cavanilles llevarán un número de identificación o referencia (Ref. 1) que indicará al lector de qué obra se trata en el epígrafe del artículo, donde sumarizamos su obra. Véase 1 , y para la edición en español 2.

(6) Refs. 3, 4, 5, 6, 7, 8, 9, 10, 13 y 14. 
Guarinos (7) que se publica en Madrid el mismo año. Sempere dirá de ella:

Hace ver en ella el estado en que se hallaba descrito por el gran Linneo en su última edición de 1780 , este género de la clase Monadelphia, ó Malvacea, en la que Linneo no conoció más de 21 especies; Mr. Lamarck, en la nueva edición de la Encyclopedia, 32; cuyo número ha aumentado el Sr. Cavanilles hasta el de 82; sacando este aumento considerable de los herbarios Commerson, Jusieu, Dombey, Aublet, Adamson y otros. El autor ha cultivado por sí mismo 26 especies vivas, cuyo trabajo constante y atento le ha hecho descubrir que, ó no habían visto los otros, ó no habían conocido su importancia, ya también en el número de semillas que contenía cada una de aquellas; con otras observaciones interesantes, sobre la colocación de los estambres, figura y proporción del caliz etc. Además de las 82 especies de sidas, pone otras sin plantas parecidas á ellas, pero diferentes en el fruto, á las que el autor ha puesto nombre propio, dando a dos de ellas los de Palaua y Triguera, en obsequio a los Botánicos Españoles amigos suyos. Para hacer más perfectible sus observaciones, pone el autor al fin de su obra doce láminas, de las quales ha dibuxado por sí mismo ocho, y dirigido el trabajo de las demás, persuadido de que jamás son exactas las estampas botánicas, sino quando están hechas o corregidas por los mismos Profesores. (8).

Como vemos, todo un modelo de trabajo científico que además es un buen perfil de algunas de sus más notorias peculiaridades en ésta y la siguiente etapa: amplio conocimiento de lo último realizado en las vanguardias botánicas de Europa, afán por aumentar el número conocido de especies conocido, bautizo de algunas de ellas con nombre de españoles eminentes en nuestra historia científica y meticulosidad en el trabajo. Amplio programa científico que no le impediría entablar jugosas polémicas durante su estancia en París, y luego en Madrid, con Casimiro Gómez Ortega, Hipolito Ruiz, Friedrich C. Medicus, Charles Louis l'Heritier (9).

Ya en Madrid, regresado en 1789, recibe el encargo de estudiar la flora española por parte del Rey. Con este fin comienza a hacer incesantes viajes por toda la geografía española a partir de

(7) J. Sempere y Guarinos Ensayo de una biblioteca española de los mejores escritores del reynado de Carlos III. 3 vols. Madrid, Gredos 1969, Edición facsimil (1." ed. 1785).

(8) Ibid., págs. 171-172.

(9) Ref. 18. 
1791. Fruto de esta tarea salen a la luz en 1795 y 1797 los dos tomos que componen las Observaciones sobre la Historia Natural, Geografía, Agricultura, Población y Frutos del Reyno de Valencia (10). Esta obra, a diferencia de las anteriores que versaban exclusivamente sobre botánica, está escrita en lengua vulgar, en español. Las ideas que en ella vierte, son consideradas por distintos especialistas (11) de vanguardistas y con un sano sentido del equilibrio (12) y la independencia. En 1797 fue nombrado miembro numerario de la Real Academia de Medicina, en 1799 colabora, junto con Cristiano Herrgen, Luis Proust y D. Fernández en la fundación, por orden real, de los Anales de Historia Natural de los que hablaremos más adelante; y en 1801 es nombrado catedrático de botánica y director del Real Jardín Botánico de Madrid, en que sucede a Casimiro Gómez Ortega, y que conservará hasta su muerte, tres años más tarde (1804). Durante ese breve período mejoró notablemente el Jardín ya que, según Costa Talens (13), construye nuevos invernaderos y estufas, aumenta el número de plantas cultivadas de 3.000 a 7.500, organiza el Jardín con el sistema sexual de Linneo, modificado por Jussieu y reducido a su vez de veinticuatro clases a quince por Cavanilles, amplía el herbario -que contaba con 1.507 pliegos-, hasta 12.000, incorpora las colecciones botánicas de Née de plantas recogidas por todo el mundo; de Thalacker, de plantas de Sierra Nevada; de Lagasca, de muestras de León y Asturias, Rodríguez con especímenes andaluces, además de su propio hervario, y amplió la biblioteca en 1.500 volúmenes (14). Legado ingente que enriqueció en sus "Discursos y Demostraciones», publicados o no, y sus enseñanzas a alumnos como Lagasca y Clemente (15).

En cuanto a sus soluciones y deseos, manifiesta conmiseración por la pobreza campesina y un deseo de que los hombres del campo innoven, pronto a encontrar o proponer soluciones si (y

(10) Ref. 17.

(11) El relieve en las "Observaciones sobre el Reyno de Valencia" (17951797), Cavanilles. Naturalista de la Ilustración, 1745-1804. Madrid, Real Jardín Botánico, 1983, pág. 47, MATEU BElles.

(12) Con referencia a este aspecto nos parece positivo destacar su decisión con respecto a la toponimia valenciana: "Los nombres de los lugares van escritos como hoy día se pronuncian, a excepción de Murviedro, y algun otro que el uso no ha consagrado: lo contrario siempre me ha parecido un abuso perjudicial". 17 pág. XII del primer tomo.

(13) Costa TALENS "La obra botánica de Cavanilles", Cavanilles. Naturalista de la Ilustración, 1745-1804. Madrid, Real Jadín Botánico, 1983.

(14) Ibid., págs. 20-21.

(15) Con referencia a este aspecto, parece muy importante a los ojos de los botánicos su obra, 50 . 
sólo si) las cosas no van bien, divulgador, aficionado al lado positivo de las cosas. Cavanilles es crítico con la rutina en el cultivo; con los ataques interesados contra su patria; la aristocracia terrateniente despreocupada por sus posesiones; con el clero que cobra sin servir al humilde a cambio; con la medicina estancada sin búsqueda de soluciones; con otros científicos, con los que no está de acuerdo; con las talas de árboles indiscriminadas y al miedo popular a la vacuna contra la viruela. Sin embargo, nuestro abate recoge y alaba la laboriosidad del campesino, la iniciativa personal para el progreso, sea botánico, fraile o campesino, así como la labor de nuestros sabios botánicos españoles olvidados en el tiempo. Nos legó una ingente e interesante obra botánica, un Real Jardín Botánico ampliado y mejorado, un sistema linneano de clasificación botánica modificado por Jussieu y perfeccionado por él mismo, una visión integrada y erudita que no es en absoluto menos importante, una muestra de cómo enlazar lo «antiguo» y lo «moderno» en una sola obra.

\section{UNA SELECCIÓN DE SU OBRA}

Su abundante obra es, del mismo modo que en caso de su vida, fácilmente localizable en los repertorios bibliográficos habituales (16). Se caracteriza por ser escrita en su totalidad en la última etapa de su vida, y durante su paso por París. Se puede clasificar básicamente en tres etapas:

\subsection{París (1784-1789)}

1. Observations de ... sur l'article Espagne de la nouvelle Encyclopedie. Paris, 1784.

2. Observaciones sobre el artículo España de la Nueva Encyclopedia. Traducida al Castellano por don Mariano Ribera. Madrid, 1784.

3. Dissertatio botanica de Sida et de quibusdam plantis quae cum illa affinitatem habent. Paris, 1785.

4. Secunda dissertatio botanica De Malva, Serra, Malope, Lavatera, Alcea, Althea et Malachra. Accedunt Sidae mantissa et

(16) Francisco Agullar PIÑal. Bibliografia de Autores Españoles del Siglo XVIII. Tomo II, C-CH. Madrid, CSIC. 1983. J. M. LóPEZ. PIÑERo y otros. Diccionario histórico de la ciencia moderna en España. Vol. I (a-l). Barcelona, Peninsula, 1983. 
tentamina de Malvarum atque Abutilonis fibris in usus oeconomicos praeparandis ... Paris, 1786.

5. Tertia dissertatio botanica, De Ruizia, Assonia, Dombeya, Pentapete, Malvavisco, Hibisco, Laguna, Cienfuegosia, Quararibea, Pachira, Hugonia, et Monsiona ... Paris, 1787.

6. Quarta dissertatio botanica. De Geranio, CXXVIII species complectens, XLIX tabulis incisas ... Paris, 1787.

7. Quinta dissertatio botanica. De Sterculia, Kleinhovia, Ayenia, Buttneria, Bombace, Adansonia, Crinodendro, Aytonia, Malachodendro, Stewartia ey Napacea. Accedit praecedentium dissertatione mantissa, XXXVI tabulis aere incisis ornata ... Paris, 1788.

8. Sexta dissertatio botanica. De Camellia, Gordenia, Marisonia, Gossypio, Waltheria, Melochia, Mathernia, Hermannia, Urena, Malisia, Styrace, Galaxia, Ferraria et Sisyrincho. Accedint mantissa tertia, XLI tabulis aere incisis ornata ... Paris, 1788.

9. Septima dissertatio botanica. Quatordecim genera monadelphia continens, XXIV tabulis accurate delineata ... Paris, 1789.

10. Octava dissertatio botanica Erythroxylon et Malpighia complectens, XVIII tabulis ornata ... Paris, 1789.

11. Carta de ... en respuesta a la que se insertó en la segunda parte del Memorial Literario del mes de Septiembre de 1788, donde se hace crítica de sus Disertaciones botánicas por unos que se titula vecino de Lima. Madrid, 1789.

12. Observationes in quintum fasciculum D. L'Heritier. Paris, 1789.

\subsection{Madrid (1790-1799)}

13. Nona dissertatio botanica De Banisteria, Triopterids, Molinaet Flabellaria. XXIII tabuli ornata ... Madrid, 1790.

14. Decima dissertatio botanica. De Passiflora. XXXII tebulis ornata ... Madrid 1790.

15. Monodelphiae Classis Dissertationes Decem ... Madrid, 1790.

16. Icones et descriptiones plantarum quae aut sponte in Hispania crescent, aut $i$ Hortis hospitantur. Madrid, 1791-1801. 6 vols. (los 5 primeros volúmenes son de esta etapa).

17. Observaciones sobre la Historia Natural, geografía, agricultura, población y frutos del Reyno de Valencia. 2 vols. Madrid, 1795-1797. (Nosotros utilizaremos una edición fascimilar publicada en Valencia en 1981).

18. Colección de papeles sobre controversias botánicas de ... 
con algunas notas del mismo a los escritos de sus antagonistas. Madrid, 1796.

19. Observaciones sobre el cultivo del arroz en el Reyno de Valencia. Memorias de la Real Academia Médica de Madrid, 1:99. 128. 1799.

\subsubsection{Madrid/Real Jardín Botánico (1799-1804)}

20. Descripción de cinco géneros nuevos y de otras plantas, por ... Anales de Historia Natural (AHN), I, 1:33-45. 1799.

21. Botánica. De los géneros Goodenia y Scaerola ... A.H.N. I, 2:89-107. 1799.

22. Nuevos caracteres genéricos de los Helechos por Smith. ANH I, 2:108-115. 1799.

23. Historia natural de las palomas domésticas de España y especialmente de Valencia, por ... AHN I, 2:146-176. 1799.

24. Observaciones sobre el suelo, naturales y plantas del Puerto Jackson y Bahía-Botánica. AHN I,3:181-245. 1800.

25. Observaciones botánicas. A.H.N. I, 3:340-245. 1800. 1800 .

26. Materiales para la historia de la botánica. $A H N$ II, 4:3-57.

27. Del terremoto que se observó en el Reyno de Quito en 1797. AHN II, 4:91-104. 1800.

28. Polvos contra la rabia. $A H N$ II, 5:178-195. 1800.

29. Del Sinfito Petreo $A H N$ II, 6:271-278. 1800.

30. De las plantas que el Ciudadano Augusto Broussonet colectó en las costas septentrionales de la Africa y en las Islas Canarias. Anales de Ciencias Naturales (ACN), 78. 1801. (A partir de ahora la revista pasa a llamarse con este nuevo nombre).

31. Enfermedad y muerte de un rabioso. $A C N$ III, 8:115-126. 1801.

32. Enfermedad y muerte de otro rabioso. $A C N$ III, 8:126-129. 1801.

33. Descripción de los géneros Aeginetia, Rizoa y Castelia. $A C N$ III, 8:129-135. 1801.

34. Disertación sobre el género Aro por el ciudadano E.P. Ventenat, miembro del Instituto nacional, y uno de los conservadores de la biblioteca nacional del Panteon. Traducida por D. ... $A C N$ III, 8:136-146. 1801.

35. Apéndice a la Disertación antecedente. Por D. ... $A C N$ III, 8: 146-148. 1801. 
36. Descripción de dos géneros nuevos de plantas por D. ... ACN III, 9:230-234. 1801.

37. De la Juncia avellanada, o Chufas de Valencia. ACN III, 9:234-236. 1801.

38. Extracto de una memoria sobre la enfermedad y curación de tres hombres mordidos por un perro rabioso, hecha por los facultativos de los Reales hospitales de esta Corte. $A C N$ III, 9:237250. 1801.

39. Enfermedad y muerte de un hombre que murió rabioso en los Reales hospitales de esta Corte en 1 de Febrero de 1801. ACN III, 9: 250-260. 1801.

40. Funestos efectos de la rabia. ACN IV, 10:3-11. 1801.

41. De las plantas que el ciudadano Augusto Broussonet colectó en las costas septentrionales de la Africa y en las Islas Canarias (fascículo II) $A C N$ IV, 10:52-109. 1801.

42. Suplemento al género Buena. ACN IV, 10:109-120. 1801.

43. Nuevos experimentos que confirman la virtud profiláctica de los polvos vegetales. $A C N$ IV, 11:225-230. 1801.

44. Caso extraordinario en la enfermedad de la rabia. $A C N$ IV,11:230-236. 1801.

45. Del género nuevo Francoa. ACN IV, 11:236-239. 1801.

46. Extracto del primer fascículo de la obra titulada "Ticinensis horti academici plantae selectae'. ACN IV, 11:239. 1801.

47. Del género Ugena. ACN IV,12:249-256. 1801.

48. Suplemento a los artículos sobre la rabia y sus remedios profilácticos. ACN IV, 12:344-346. 1801.

49. Extracto de los quatro facículos del Jardín de J. M. Cels. $A C N$ IV, 12:346-352. 1801.

50. Descripción de las plantas que D. ... demostró en las lecciones públicas del año 1801 precedida de los principios elementales de botánicas. Madrid, 1802.

51. Discurso que ... leyó en el Real Jardín Botánico de esta Corte el día 1 de Abril de 1802. ACN V, 14:11-134. 1802.

52. Medicina militar. Fragmentos de colección de observaciones que R. Desgenettes hizo en el exército de oriente $A C N \mathrm{~V}$, 14:218-223. 1802.

53. De la cigüeña blanca. $A C N \mathrm{~V}, 15: 234-244.1802$.

54. Observaciones botánicas. $A C N \mathrm{~V}, 15: 245-263.1802$.

55. Discurso que ... leyó en el Real Jardín Botánico de esta Corte en 13 de Abril de 1803. ACN VI, 16:119-138. 1803.

56. Discurso sobre algunos botánicos españoles del siglo XVI, 
leído en el Real Jardín Botánico al principiar el curso de 1804. $A C N$ VII, 20:99-140. 1804.

57. Del género nuevo Viviana. $A C N$ VII,21:211-212. 1804.

58. Adición al artículo del licenciado Robles citado en la nota segunda de la pág. 120. $A C N$ VII, 20:216 1804.

59. Botanical Observations by the late D. Antonio Joseph Cavanilles, translated from the Spanish. Annals of Botany I, 2:409422. Londres, 1805.

La primera etapa de sus publicaciones podemos clasificarla, sin menosprecio, de inicial, ya que en ella muestra por primera vez su vena botánica, polemista y de historiador de la ciencia española con una gran madurez y temple. Tanto es así que sus Dissertatio Botanica de Sida... son bastante bien consideradas por los estudiosos de su aportación botánica (17). Su primera obra, destacable por su importancia histórica es una vibrante defensa, nunca desatendida en el resto de su obra, de la importancia de la ciencia española.

La segunda fase se puede destacar por su considerable volumen botánico. Numerosas monografías con nuevas especies y géneros botánicos surgen gracias a la colaboración de múltiples ilustrados y especialistas de la época. Es también, la época en que realizan fecundas y amplias herborizaciones por toda España y, en especial, por el área valenciana.

El último período, que hemos denominado Madrid/Real Jardín Botánico es la etapa de más interés para este estudio, dado que será durante estos años cuando se manifiesten con más claridad sus intereses y afanes de investigador: historia de la ciencia, animales, la rabia, el combate contra ella, la divulgación y enseñanza de los españoles que nos antecedieron, la promoción de la mejora del país. Todo ello repartido en numerosos y breves artículos, en discursos cuya aparente diferencia temática no oculta su pensamiento totalizador del mundo natural incluyendo en él al hombre.

(17) Véase para esta fase y la siguiente: Enrique Ál.varkz López. "Cavanilles. Ensayo biográfico-crítico", Anales del Jardín Botánico de Madrid, 6, I, 1946, págs. 1-64. Y, "Noticia acerca de las plantas estudiadas por Cavanilles y en particular las recolectadas por Luis Née", Revista de Indias, Vol. VII, n² 24, Madrid, 1946, págs. 502-540. 


\section{LA BOTÁNICA DURANTE LAS POSTRIMERÍAS DEL SIGLO XVIII}

Nuestro análisis se basará fundamentalmente en la obra redactada y publicada durante la última etapa mencionada y en sus Observaciones ... sobre el Reyno de Valencia. Hay que tener en cuenta que, a diferencia de la última que hemos mencionado, no constituye una obra, sino numerosos artículos de diferentes temas inscritos dentro del campo de la historia natural y aparecidos en una revista cuya confección y existencia dependía en gran medida de las aportaciones de Cavanilles.

Durante la segunda mitad del siglo XVIII la ciencia europea sufre una profunda transformación que, basada en su propia dinámica interna y en la profesionalización de esta disciplina lleva al planteamiento de semejantes actividades como una labor útil o positivamente ventajosa para el país o para la propia gloria de la Corona y el progreso general. Dicho proceso llevó a un replanteamiento que obligaba desde el punto de vista temático y conceptual a la inclusión y conocimiento de un universo cada vez más grande y complejo de aceptar y entender.

El afán de comprensión característico de la Ilustración llevó, en buena lógica, a la orientación del método de trabajo hacia técnicas más totalizadoras que incluyesen lo "real». De modo que hacia 1790 era comúnmente aceptada la tremenda importancia que tenía la observación realizada en el campo. Cavanilles se puede incluir, sin duda alguna, en esta corriente. Sus Observaciones sobre el Reyno de Valencia (1795-97), como apunta Mateu Bellés (18) le incluyen en ella. El botánico viajó por aquel Reino aunando a sus observaciones la encuesta sistemática, y comprobando ésta última con distintas documentaciones accesibles (19). Ante la carencia de información fiable y actualizada sobre su región: "Creía que podían ser más útiles mis viajes si a las observaciones botánicas añadía otras sobre el reyno mineral, la geografía y agricultura; puesto que apenas teníamos cosa alguna» (20). Programa de trabajo que, a diferencia de sus contribuciones sueltas en los Anales, parece acercarse más a los propósitos de la historia natural y moral, y que analizaremos en el último epígrafe de este artículo.

Sin embargo, el acuerdo no era tan general en la concepción teórica como para que articulase y englobase al mundo. Los

(18) Vid. [11].

(19) Ref. 17, I: 1.

(20) Ref. 17, I: 1. 
naturalistas "profesionales» (21) fueron, por aquellos tiempos en su inmensa mayoría "fijistas». Tuvo que ser en otros ambientes no sustentados directamente por el estudio de la naturaleza, donde se comenzaran a plantear criterios evolucionistas. El progreso, la razón, la utilidad, son conceptos acuñados durante el siglo XVIII, que promovieron el fenómeno científico y evolucionista del XIX. No obstante Buffon mostró en algunos momentos una vena evolucionista no siempre mantenida o sostenida. En sus Epoques de la nature (1778) planteó un tipo de evolucionismo geológico y del mundo que es particularmente similar a las teorías que sobre el tema defendía Cavanilles. Aunque este último pudo tener más influencia en Cavanilles por medio de su amigo Lamarck, creador de esta escuela. Tanto él como el abate eran "fijistas» en botánica, aunque ambos comienzan a incluir una segunda dimensión a la cadena de la vida o "scala naturae» dado que ésta, no sólo se extendía en el espacio, sino también en el tiempo.

Este fue un período revolucionario en casi todas las disciplinas de la ciencia, así como en política y cultura. En astronomía produjo las hipótesis nebulares de Laplace y Herschel, y los comienzos de la astronomía sideral sistemática; en óptica, el renacimiento de la teoría ondulatoria de la luz; en electricidad, el descubrimiento y estudio de la misma; en las ciencias de la tierra, la creación de la paleontología y la geología estratigráfica; en antropología, el surgimiento de la craneología; en química, el trabajo de Lavoisier y Dalton; en botánica, Jussieu y Candolle; en zoología, Lamarck y Cuvier; sin decir nada de las revoluciones americana y francesa, la revolución industrial y las revueltas románticas. Sin lugar a dudas había algo en las condiciones sociales, intelectuales y espirituales de aquel tiempo que reunió e incluso exigió nuevos caminos de pensamiento (22).

Ahora bien, y continuando esta "puesta en escena» de Greene, este profundo cambio intelectual no surgiría de la nada. En España existía una tradición lo suficientemente variada y rica como para que el nuevo camino, reconociendo la obvia e indu-

(21) Joaquín Templado. Historia de las teorias evolucionistas. Madrid Alhambra, 1982.

(22) John C. GREene. "The History of Science and the History of Linguistics, Studies in the History of Linguistic:s. Traditions and Paradigms. (ed. D. Hymes) Bloomington, Ind. Indiana University Press. 1974, pág. 497. 
dable influencia del pensamiento francés, se desarrollase asentada en sus propias raíces. Este fue el caso de Cavanilles.

Ese "pseudo-cisma" al que nos hemos referido anteriormente, enmarcado en una edad revolucionaria culturalmente hablando, era tanto más acentuado cuanto la botánica, poco tiempo antes, transformada por Linneo, se encontraba atrapada muy a su placer en las ingentes cantidades de especímenes recolectadas por los viajeros en sus herborizaciones por las más ignotas regiones del mundo (23). El resto era conocer y organizar la escala natural, conocer su cultivo, posibilidades, mejora y otras utilidades para el hombre. En semejantes circunstancias, tan cerca del objeto empírico de su estudio, es muy probable que el botánico encontrase poco razonable cualquier tarea no relacionada directamente con la clasificación de toda esa nueva información que tenía en las manos.

Semejante labor, la descriptiva y clasificativa, es precisamente la que ha venido realizándose por aquellos autores que han escrito historias naturales y morales desde hacía, al menos, dos siglos. Claro está que ahora la historia natural será descrita y clasificada con un método nuevo, el sistema sexual de Linneo. Historia natural, que según el Diccionario de Autoridades, son dos términos unidos que se aplican en el caso de la naturaleza a «la descripción de las cosas naturales, animales, vegetales, minerales, etc. como la historia de Plinio, la del P. Acosta, la de Dioscórides, etc.».

\section{El MÉTODO BOTÁNICO}

La botánica, según Cavanilles, "Vióse limitada por muchos siglos a un corto número de plantas medicinales, descritas sin método, sin principios sólidos, sin arte, y con nombres muy diversos de los actuales" (24). Habitualmente, este tipo de declaraciones suele tener una segunda cláusula implícita: que algo ha cambiado o tiene que cambiar en esa disciplina si se quiere estar al día. Y eso fue, en efecto, lo que ocurrió. Cavanilles no rechaza

(23) De hecho las vanguardias botánicas de Europa tenían su residencia en aquellos lugares donde las expediciones cientílicas o los intereses de compañias comerciales con actividad fuera del continente existían. Con respecto a esta conexión puede consultarse a: A. G. Morton. History of Botanical Science, New York, Academic Press, 1981.

(24) Ref. 26, pág. 3.

\section{R. I., 1992, nus 195/196}


con ello la tradición científica española que hemos dicho que reivindicaba sino, simplemente, que la consecución de nuevos objetivos en una sociedad que se ha visto sometida a profundos cambios requiere nuevos métodos.

La gran cantidad de material botánico recolectado, el profundo interés por el progreso y bienestar social, entre otros factores, llevaron a la reivindicación de la objetividad, perfección y sistematización del método que hubiese de ser empleado. John Locke, uno de los ideólogos reconocidos de la ciencia moderna, delineó el método de trabajo científico en su Ensayo sobre el entendimiento humano (1690).

Cuando Locke escribió «El modo de mejorar nuestro conocimiento... es obtener y fijar en nuestras mentes ideas claras, distintas y completas", difícilmente podía haber afirmado más clara y distintivamente lo que los botánicos deberían hacer, y que en alguna medida, intentaban hacer: describir plantas con diagnósticos completos y establecer un sistema generalmente aceptado y estable de nomenclatura (25).

El volumen de plantas era monstruoso, las técnicas de descripción y clasificación tenían que universalizarse todo lo posible (26). Sin embargo, el problema era clasificar; ¿pertenecen las plantas a determinadas familias o clases naturales? ¿Es natural la agrupación que de ellas estamos haciendo?

Para Cavanilles, que se aprovecha de los resultados de esta polémica entre sistemas de clasificación, estos antiguos autores no sirven "por cuya razón (los nombres distintos a las actuales especies y las incompletas descripciones) quedaron poco menos que inútiles las obras botánicas de Hipócrates, Nicandro, Teofrasto. Igual suerte las de los Romanos hasta Plinio, en cuyo tiempo se llegaron a conocer mil plantas. Iba descuidándose la Botánica al paso que se arruinaba el Imperio Romano, y casi llegó a olvidarse de todo punto... (27).

Reclamaba la necesidad de un método todo lo válido posible, ya fuese éste acabado o no, un método que como él dice, intentase «encadenar las infinitas formas, los resortes sin número, los

(25) MorTon [23], pág. 236.

(26) Téngase en cuenta que el proceso al que me refiero tiene su comienzo, si éste se puede fijar, mucho tiempo antes, al final del siglo XVIII y en el XVII. MORTON [23].

(27) Ref. 26, págs. 3-4. 
secretos admirables de la naturaleza" (28), ya que para conocer "es indispensable adoptar un método o sistema" (29).

Los métodos existentes hasta el momento podían ser de dos clases: naturales y artificiales. Los primeros se basaban en «la constante conformación de las semillas, modo de desplegar sus hojas seminales, y situación respectiva de los órganos de la generación; 2, porque las clases son los resultados de hechos naturales y uniformes; 3 , porque los órdenes o familias tienen caracteres determinados" (30). Sin embargo, el método de clasificación por sistemas naturales no ha sido completado nunca por nadie $y$ sufre frecuentes interrupciones en la cadena de la vida. En el sistema artificial es el autor del mismo quien impone sus propias reglas sobre las plantas.

El método elegido por Cavanilles es el sistema de clasificación sexual de Linneo. Semejante adopción, en una mente ordenada y lógica como la suya suponía, como veremos, toda una revolución en el método de aproximación al mundo natural. Gracias a ello se colocaba además en la cresta de la ola del pensamiento científico del momento. "La más significativa conclusión a la que se llegó a partir del reconocimiento de la función sexual de la flor (clave del método linneano) fue que tanto el reino de las plantas como el animal mostraron las mismas leyes de generación tal y como Boerhaave había señalado (31). La aparente diferencia entre la reproducción en las plantas y los animales había sido un rompecabezas desde la antigüedad, y éste fue repentinamente resuelto de un modo que extendía el reino del orden racional, del mismo modo en que Newton había entendido el mundo de la mecánica, al mundo de los seres vivos» (32).

En botánica la ampliación del reino racional y objetivo centraría en mayor medida el interés por las descripciones y clasificaciones. Linneo, basado en el descubrimiento del sexo de las plantas desarrolló el método de la época; que vino, como explica y defiende Cavanilles, para perfeccionar las técnicas botánicas y universalizar su aplicación. El método de Cavanilles, del mismo modo que el de Linneo, se basaba en un profundo empirismo y en la búsqueda de las relaciones artificiales. Sin embargo no era oro todo lo que relucía. La reivindicación de verdad no va nece-

(28) Ref. 26, pág. 16.

(29) Ref. 26, pág. 16.

(30) Ref. 26, págs. 11-12.

(31) MORTON [23], pág. 238.

(32) Ref. 26, págs. 11-12. 
sariamente adscrita a la práctica de una actividad basada en la observación directa de la naturaleza. La subjetividad y las categorizaciones morales abundan en sus descripciones y clasificaciones.

No es raro encontrar en sus descripciones y análisis de ciertos animales términos como acariciar, indignación, timidez, carácter, consorte, cariño, etc... (33). En el reino botánico la humanización a la que nos referimos es menos evidente, las descripciones, más técnicas que las de animales, permiten enmascarar con mayor facilidad categorías o términos como "viudedad» de la planta hembra sin macho que la fecunde.

Asimismo, la humanización no existe solamente en el campo metodológico. Los ataques e intereses de los investigadores, su capacidad de crítica, están fuertemente motivados por los sentimientos nacionales. Cavanilles, a partir de su defensa de la ciencia española en su réplica al artículo de Masson de Morviliers sobre España en la Nueva Enciclopedia (34), dedica sus esfuerzos a la investigación y divulgación de la ciencia española. Tiene un interés divulgativo que se desarrolla bajo una perspectiva nacionalista y no altruista; por ello llevará a cabo gran parte de su tarea para reivindicar el lugar que España ocupa o debería ocupar entre los países más avanzados. Del mismo modo, y en útil contrapartida a éste, otros países también divulgan con los mismos objetivos nacionales.

Inflamada la Europa y hasta los mismos Soberanos a favor de las ciencias, y especialmente de la Botánica, se pensó en los viajes alrededor del mundo, y se emprendieron con el fin laudable de procurar la felicidad á los Indios, y de promover la Física, la Astronomía, la Navegación y las Ciencias naturales, dieron el exemplo a las demás naciones la Francia y la Inglaterra, y nombraron xefes de las primeras expediciones a Bougenville y á Cook (35).

La dinámica claramente expuesta por el propio Cavanilles es lo que en la actualidad, en teoría de sistemas, se conocería como un circuito de retroalimentación positiva, donde la carrera o pugna nacionalista por alcanzar la excelencia o supremacía científica, requiere cada vez mayores logros al acercarse a la deseada

(33) Ref. 23, pág. 148.

(34) Refs. 1 y 2.

(35) Ref. 26, pág. 31. 
e inalcanzable meta. Cierto es también que en el ámbito donde mayor enfrentamiento existe es en el de los gobiernos y las Coronas dado que, en general, los científicos, pese a algunas furiosas enemistades, sienten junto a cierta xenofobia crítica, un impulso más altruista, más cosmopolita y deseoso de un desarrollo positivo, generalizado y útil. Así cuando Loefling, discípulo de Linneo,

«...más dichoso ó más instruido descubrió varios géneros Matritenses que comunicó á Linneo: á vistas de los quales declamó este contra los Españoles en términos poco dignos, que tal vez hubiera moderado sin la ignorancia que tenía de nuestra historia literaria; si hubiera visto las obras de Laguna, de Esteve, de Collado, de Cobo y de otros sin número que cultivaron la Botánica: [...]. Pero perdonémosle las expresiones que le arrancó no el odio a nuestra nación, sino el ardiente zelo que tuvo a la Botánica; y hagamos ver al mundo con nuestras obras, que, despiertos ya de aquel letargo en el que nos suponían, aspiramos a un lugar distinguido entre los Botánicos de la actual generación» (36).

Hasta aquí hemos dibujado un panorama de la investigación en la que se inscribe Cavanilles donde sus opiniones actuaban como nuestra guía en el universo científico del XVIII. Sin embargo, y dejando aparte esa concatenación de lo objetivo y lo subjetivo en un método razonado, ¿podemos hacernos una idea clara del tipo de investigación científica que preconizaba don Antonio José Cavanilles? Afortunadamente su afán divulgativo y pedagógico han permitido que, en la impresión de sus discursos y numerosos artículos sobre las ciencias naturales, llegasen a nosotros sus opiniones sobre el proceder adecuado. Generalmente Cavanilles opta, cuando explica qué es y cómo se debe trabajar en esta ciencia, por un encuadre histórico que permite al lector comprender las razones de tal procedimiento. Su interés por ser explícito y claro le lleva a no rehuir las explicaciones, de modo que no es difícil localizar definiciones de botánica como la que sigue: «...la Botánica, que abraza quanto vegeta sobre la tierra ó en las aguas; que indaga la textura de los órganos vegetales; el oficio ya peculiar, ya mutuo de cada uno; que escudriña lo íntimo de las semillas para conocer y distinguir las plantas. [...]; con todo, es regularmente tan exacta la ciencia de los vegetales,

(36) Ref. 26, pág. 25. 
perfeccionada como hoy la tenemos que ninguna de las naturales la lleva exceso en exactitud" (37). Concebía la naturaleza como una realidad fija, constante, impresa por la mano del Hacedor. Intentaba con ello el abate «elevar el alma racional al origen de todo ser y de toda existencia" (38). Ahora bien, semejante deismo, característico de la Ilustración, no impedía el establecimiento de un método científico analógico encadenado a la maravilla de la obra divina. "Si un viviente de esta naturaleza, cuya vida fugaz pasa como el moho que le sirve de habitación y de alimento: si un pequeño insecto, cuya organización calculamos por la analogía que pueda tener con la de los animales conocidos, produce en nosotros un cierto pasmo, y nos fuerza á admirar el poder supremo ¿qué efecto no debe causar la contemplación atenta de los vegetales" (39)

Sin embargo, el lirismo racionalista, si así puede llamarse, que exhibe nuestro autor no le exime de dirigir fundamentadas críticas a la artificiosidad del método linneano (40) y a la ciega admiración que sus discípulos sienten por él. Es por ello por lo que, con su característico estilo reclama y valora las aportaciones personales, propias de cada investigador y modifica el sistema sexual de Linneo simplificándolo, dado que «es preciso rectificar muchas veces las ideas, principalmente las compuestas, como son las de un sistema ó método" (41).

El método de Cavanilles es claro y sistemático, pretende la comprensión del mundo natural en su totalidad, mediante la integración del mismo en un único sistema de conocimiento. El objeto no es el saber por el saber, existen finalidades importantes que subyacen y guían el trabajo que realiza. Desea, en la investigación, un clima de cooperación intelectual internacional o «hermandad para promover la ciencia" (42): destaca la labor conjunta de investigación que llevan a cabo los botánicos de gabinete y los de campo en sus expediciones a los más distintos ámbitos del mundo (43); aprecia el valor que las expediciones científicas han tenido para el desarrollo de la ciencia botánica (44); y, además,

(37) Ref. 55, pág. 122.

(38) Ref. 51, pág. 111.

(39) Ref. 51, pág. 112.

(40) Ref. 55, pág. 129.

(41) Ref. 55, pág. 133.

(42) Ref. 26, pág. 21. En el mismo párrafo plantea como ejemplares las relaciones epistolares entre Linneo y Bernardo de Jussieu.

(43) Ref. 26, pág. 30.

(44) Ref. 26, pág. 24. 
encuentra en la disciplina un valioso aporte al desarrollo de la prosperidad y salud nacional (45).

El rechazo del pueblo a las tareas de investigación en esta área de las ciencias está en íntima conexión con su sentido pedagógico y divulgativo. Solo así, mediante la instrucción del "vulgo" podrá darse cuenta éste de la benéfica influencia de, por ejemplo, los árboles y su papel en el equilibrio ecológico (46). Reclama, asimismo, una ciencia acorde con la sencillez que requiere la enseñanza: "no basta dominar la ciencia, ni explicar con facilidad lo sublime de ella: es indispensable baxar antes a lo insípido de los elementos, reducirlos al menos número posible, y evitar quanto pueda causar fastidio a los discípulos: es preciso mostrarles desde luego un método fácil y seguro; llevarlos como por la mano a resolver los primeros problemas, a que resuelvan algunos sin auxilio, para que se alienten y convenzan de que pueden hacer progresos si siguen con tesón, si oyen con cuidado la doctrina del profesor» (47).

\section{ANÁLISIS DE LA TEMÁTICA DE LA OBRA}

Basándonos en la tercera etapa que habíamos calificado en su producción (Madrid/Real Jardín Botánico), hemos podido definir y considerar su método y peculiaridades. Ahora bien, para tratar si su obra está construida desde una óptica de Historia Natural y Moral, es necesario que incluyamos en nuestro estudio las Observaciones... sobre el Reyno de Valencia. En este epígrafe nos proponemos entrar en las consideraciones siguientes: ¿existió durante el siglo XVIII una Historia Natural y Moral?, ¿es posible hablar de una Historia Natural y Moral basándonos solamente en los que en el XVIII ellos llamaban historia natural?, ¿es la historia natural del XVIII un desarrollo de la Historia Natural y Moral?

En el prólogo a la publicación se indican los objetivos que esta obra tiene: 1. propagar "con la mayor brevedad» los descubrimienos y hechos que hace España en "Mineralogía, Química, Botánica y otros ramos de Historia Natural" así como los hallazgos y avances extranjeros; y, 2. La utilidad y el progreso del

(45) Ref. 51, págs. 143-32.

(46) Ref. 51, págs. 114-15.

(47) Ref. 55, págs. 120-21. 
conocimiento y el estado de la nación (48). Dos años después, en 1801, se cambia el nombre de la publicación y se llamará Anales de Ciencias Naturales. Los primeros objetivos de los Anales habían sido cumplidos y ahora el título tenía que ampliarse para incluir todo "lo perteneciente a la historia natural, y a las ciencias que por cualquier título tratan de la naturaleza" (49). La modificación del nombre transforma poco su contenido, publicación de algunos artículos y hallazgos extranjeros, cálculos, botánica y noticias sobre medicina española son sus contribuciones habituales. Los Anales insisten en aquellos aspectos donde otras naciones no han conseguido tantos avances, intentando mostrar, en el caso de Cavanilles, la larga tradición histórica que conduce el estudio e investigación en alguna de estas disciplinas «naturales».

La obra de Cavanilles en los Anales es cuantiosa, y su influencia en ella decisiva, ya que desde el comienzo toma las riendas de la misma. De hecho los especialistas la conocen con el subtítulo popular de los "Anales de Cavanilles». De los cuarenta y cinco artículos que publicó en el lustro de duración de la misma (50), cinco fueron los que consideraremos sus temas básicos: Australia, Historia Natural de las palomas domésticas, sobre la rabia, Botánica e Historia de la Botánica o de la Ciencia. Fuera quedan algunos extractos y traducciones además de las importantes Observaciones sobre la Historia Natural, Geografia, Agricultura, Población y Frutos del Reyno de Valencia, (que será objeto de nuestro interés más adelante).

Todos los temas que he enumerado tienen un denominador común: la historia natural. Una historia natural que se entronca, o puede entroncarse, con la tradición abierta en España por las historias naturales y morales. Ahora bien, la descripción no es definición y nosotros, líneas antes, pedimos a nuestro autor una definición clara que ayude a pronunciarnos sobre la continuidad o ruptura del desarrollo intelectual de nuestro país. La historia natural se ocupa, según declara Cavanilles en sus Principios elementales de Botánica (51), de "cuanto existe en lo interior de nuestro globo o en su superficie». Se ocupa de los fósil o mineral "cuerpo compuesto de partes agregadas sin organización», lo animal "orgánico con vida y movimientos expontáneos», y lo

(48) Prólogo de los Análes de Historia Natural, I, 1799, págs. 3-4.

(49) Advertencia preliminar con respecto al cambio de nombre de los Anales de Historia Natural y por qué se elige el de Anales de Ciencias Naturales, III, 7, 1801 , pág. 3.

(50) De hecho los Anales no sobrevivieron a su muerte, acaecida en 1804.

(51) Ref. 25, pág. 7. 
vegetal «sin movimiento alguno expontáneo» (52). En historia natural, dice Cavanilles, «nos debemos contentar con su descripción hasta que perfeccionada su historia con nuevas observaciones se determine el género" (53), y así, una vez clasificadas, pueda "completar su historia» (54). El objetivo de la elaboración de una historia natural es, en una primera fase, la obtención de aquellas cosas útiles para ilustrar su historia, esto es "sus pasiones, costumbres y economía" (55), así como otras muchas observaciones que muestran, tal como se observa en su obra, la integración en un todo coherente y organizado mediante leyes reconocibles por la razón (56).

Como muy bien anuncia el viejo refrán popular, «del dicho al hecho va mucho trecho». Hemos revisado las opiniones que $\mathrm{Ca}$ vanilles expresó acerca de la ciencia, botánica en general, de la tradición naturalista y de la necesidad de aplicación y divulgación de los nuevos conocimientos adquiridos. Ya en el epígrafe anterior tratamos la vertiente teórica y práctica de su labor botánica y su concepción científica. Ahora bien, ¿Cavanilles integró en un solo universo los tres reinos de la naturaleza e incluyó en ellos al hombre del mismo modo en que reclamaba en sus "teorías»? ¿Ofreció en su dispersa obra una visión de conjunto ordenada, idéntica o similar al tipo de enfoque que caracterizó la Historia Natural y Moral?

Australia, la rabia y la historia natural de las palomas domésticas son el tríptico sobre el cual voy a intentar mostrar la realidad o no de su Historia Natural y Moral en los Anales: la evolución, en clave ilustrada, de este supuesto género. ¿Será en estos artículos que se acercan a fragmentos de la realidad natural donde descubramos a finales del siglo XVIII y principios del XIX una Historia Natural y Moral?

(52) Ref. 25, pág. 7.

(53) Ref. 24, págs. 204-5.

(54) Ref. 24, pág. 206.

(55) Ref. 23, pág. 147.

(56) A esta tarea se consagró de hecho en 16. Es una de sus obras más apreciadas por los botánicos, en ella muestra su interés por el pasado botánico español bautizando a varios géneros con el nombre de los autores de algunas de las H. N. y M.: Cobacea en la pág. 12 (vol. 1) en honor del P. Bernabé Cobo. Lopezia en la pág. 13 (vol. 1) en honor de Tomás López Medel, y Alcina en la pág. 10 (vol. 1) en honor del P. Alzina. 


\subsection{Australia}

Lo distante, lo diferente, es el ingrediente que nos faltaba en el cuadro que estamos intentando perfilar sobre la obra histórico natural y moral de Antonio José Cavanilles. Todas las obras analizadas en este volumen se caracterizan, entre otros elementos, por una técnica peculiar de aproximación a la diversidad. Se trataba de asimilar con nuestros esquemas, en la medida de lo posible, aquellas realidades o las que nuestro pensamiento no se había conformado. Australia, y el modo en que Cavanilles presenta la información cedida por Luis Née (57), es, por ello, una de las piedras de toque de nuestro análisis.

Antes de comenzar a describir su contenido es importante destacar que este largo artículo de 58 páginas (58) contiene un relato de Née en primera persona desde la pág. 184 a 201. A esta larga cita le precede una introducción al área que van a tocar, cuando se descubrió esa tierra, su primera colonización y asentamiento, y las observaciones geográficas de la Expedición Malaspina. A continuación aborda, en el relato de Née, el estado de las colonias y la naturaleza del suelo: continúa con las armas, costumbres y configuración de los naturales; describe el canguro o "kangarú», clasifica algunas de las plantas más características de esa zona de Australia.

Tras el encuadre histórico y geográfico de ese espacio pasa a perfilar, de un modo integrado al suelo, sus utilidades, sus habitantes, en tanto en cuanto están conectados con el territorio que habitan; el animal más peculiar que allí reside y alguna de las plantas de la zona. La visión integrada y de conjunto es bastante llamativa, sin embargo, a nuestro juicio, queda oscurecida por las dos clasificaciones de seres vivos no vegetales. Ambas están hechas de un modo sistemático y claro, ordenado. Y ambas plantean al autor problemas de clasificación. La primera, que es de Luis Née, está perfectamente integrada en el texto de Cavanilles. Creemos, aunque no podemos afirmarlo con toda certeza, que Cavanilles estaba plenamente de acuerdo con el relato de Née. Sea cual fuere el autor real de la misma creemos que tiene particular interés la inclusión de una nota a pie de página de ese

(57) Luis Née fue uno de los botánicos que trabajó en la expedición de Alejandro Malaspina alrededor del mundo (1789-1794).

(58) Ref. 24. 
artículo donde establece un nexo entre lo que ellos denominan vida primitiva de los aborígenes y los simios (59):

En parte alguna de mis viages he visto más degradada nuestra naturaleza, ni individuos más feos ni silvestres que en la Nueva Holanda: parecen ocupar el último grado de los hombres para pasar a la familia de los monos por el más perfecto de ésta que es el Orang-utang. Hay a la verdad entre ellos y los monos diferencias esenciales en la forma exterior, y mayores aún en la anatomía; pero ni los Cafres, ni los Hotentotes, ni los miserables de la Tierra del Fuego se acercan tanto al Orang-utang como los naturales de la Nueva Holanda (60).

La descripción y los problemas de clasificación, al igual que en el caso de los canguros que vamos a mencionar ahora, son lo suficientemente claros como para no merecer explicación alguna.

Es tan particular su forma exterior, como la disposición y número de dientes; y de aquí la dificultad de señalarle un lugar debido en el sistema animal. Penaut dio en su zoología británica la descripción del Kangarú, y por ella se ve que no pertenece al género gerboise al qual lo reduxo erradamente el autor de la nueva enciclopedia. Fundóse únicamente en la desigualdad que reyna entre sus pies y manos, sin atender a otros caracteres esenciales, cuya reunión debe formar el genérico. Así es que solamente se extiende a la especie de saco que se observa en la hembra donde oculta sus hijos y les da de mamar, puede colocarse en el género didelphis de Linneo; y así a los dientes incisiorios en el género mus y contiguo al mus iaculus del mismo autor; pero como se aparta de esto por varios caracteres» (61). ¿Dónde colocar a un animal semejante? ¿Cuales son los caracteres esenciales, los elementos que le definen en la escala contínua de la naturaleza?

La respuesta nos viene dada, afortunadamente por él mismo: "pero como se aparta de estos por varios caracteres; y como actualmente se ignoran las costumbres, el modo de propagarse, la anatomía, y otras cosas indispensables para fijar con acierto el grado que la corresponde en la serie de los quadrúpedos, nos debemos contentar con su descripción (que en el siguiente párrafo pasa a dar) hasta que perfeccionada su historia con nuevas

(59) Ref. 24, pág. 196.

(60) Ref. 24, pág. 196.

(61) Ref. 24, pág. 204. 
observaciones se determine el género" (62). Costumbre, modo de propagarse, anatomía, son algunos de los elementos que él estima convenientes para saber cuál es su lugar, para saber realmente que és y cómo entenderlo. "Es regular» concluye "que los naturalistas nos den con el tiempo noticias ciertas de este animal para completar su historia» (63). ¡Historia!, nos dice, ¿no es esta acaso una buena muestra de historia natural tal y como él la define? ¿No contiene criterios que otros autores anteriores de Historia Natural y Moral han contenido en su sección de historia moral?

La visión integrada a la que nos hemos referido ha aflorado en el "hecho». Tanto los animales como los seres humanos son incluidos en la escala natural con criterios semejantes. Plantas y minerales, hombres y animales «no racionales» pertenecen a un mismo universo, a una naturaleza que puede ser, como anunciamos en la sección teórica, en el "dicho», entendida con las mismas leyes. Ahora bien, también declaró en su Discurso que... leyó en el Real Jardín Botánico de esta Corte en 13 de Abril de 1803 (64), que existían algunas diferencias: «Si observamos los primeros períodos de nuestra existencia, y los comparamos con los de los irracionales veremos que la naturaleza prodigó á estos multitud de recursos que negó a los hombres. Nacemos desnudos, débiles, y nuestro espíritu sólo parece existir entonces para animar el cuerpo: (admira el talento instintivo del animal frente al desvalido hombre). Corre el Orang-utang acosado del frio hacia la hoguera; mas ni sabe arrimar los tizones, ni fomentar aquel consuelo que le ofreció el acaso. Muy al contrario se muestra el hombre quando tomaron fuerzas el cuerpo y el espíritu; quando se dispertó en él el deseo de saber, y empezó a gustar el sabroso néctar de la verdad; quando llegó á descubrir alguna de sus propias fuerzas" (65).

La diferencia parece clara, y además, también parece claro que en este párrafo se aleja de la concepción fijista de la naturaleza y avanza un paso hacia el evolucionismo. Se acerca a tesis mantenidas por su colega y amigo Lamarck. Mas si nos paramos a comparar el conjunto de su obra, veremos inmediantamente que su fijismo botánico no se manifiesta del mismo modo en la geología, donde reconoce abiertamente el cambio y la evolu-

(62) Ref. 24, págs. 204-5.

(63) Ref. 24, pág. 206.

(64) Publicado en ref. 55.

(65) Ref. 55, pág. 119. 
ción (66). ¿Por qué no adopta una visión coherente, y se define en este tema?

Semejante desfase ha sido atractivamente interpretado por Greene (67) con respecto al lenguaje y la historia de la ciencia en el XVII. El lenguaje se concebía en la época como «obra de los hombres» mientras que la botánica o la zoología era "obra de Dios». Es lógico, por tanto, que todo análisis de cambio y desarrollo de las descendencias de orígenes comunes, sean temas de historia natural que caen dentro de la órbita de lo teológico y de la posible herejía ¿Rebelarse contra la Biblia, la Iglesia o la doctrina para interpretar la "obra de Dios»? Es distinto, obviamente, a las interpretaciones que otras ciencias minoritarias puedan dar con respecto a temas profanos. Cavanilles era católico y para hacer ciencia pragmática no necesitaba en modo alguno chocar con concepciones opuestas a la Iglesia. Sólo la filosofía de la historia, y no la ciencia natural, conducían de un modo más concluyente a posturas evolucionistas o enfrentadas a la tradición. De ahí que en Cavanilles, que hace ciencia natural, sólo sus obras más cercanas a la filosofía de la historia contengan algún apunte de evolucionismo ilustrado (68).

\subsection{La rabia}

En su serie de artículos sobre el tema de la rabia (69) la tónica o enfoque general son muy distintos. Esta visión, que parece oscurecer el conjunto que estamos intentando caracterizar e integrar, se encuentra claramente modificada por un factor básico y predominante: el humanitarismo. «Este bosquejo» cuando nos describe cómo se desarrolla la enfermedad «que dista infinito del original basta para inflamar á quantos conserven rastros de humanidad y obligarles a buscar remedio para esta dolencia» (70). Es necesario encontrar soluciones, hay un esbozo de medicina preventiva. Y, al igual que en el resto de su obra, una estructura clara y razonada. Primero, como en botánica, define y describe el proceso para, en una segunda parte desarrollar sus observa-

(66) Véase 24.

(67) GREENE [22].

(68) Véase refs. 50 ó 51 y 55.

(69) Sus trabajos sobre la rabia se componen de las refs. $28,29,31,32,38$, $39,40,43,44,48$.

(70) Ref. 31, pág. 119. 
ciones en forma de conclusiones nuevas y críticas sobre el tema. Sin embargo, es en estos artículos donde sus planteamientos parecen estar más alejados de las antiguas historias naturales y morales.

\subsection{Historia natural de las palomas domésticas}

Aunque, desgraciadamente, sus estudios sobre la rabia no parecen confirmar las líneas que hemos querido localizar en sus planteamientos, por el contrario, la Historia Natural de las palomas domésticas de España y especialmente de Valencia ofrece desde su mismo título, más esperanzas (71). Es en este artículo donde obtenemos una de las mejores muestras de su concepción práctica de la historia natural. Considera a las palomas fáciles de distinguir; sin embargo los caracteres genéricos son más difíciles de conocer. Opta por clasificar a las palomas por su tipo de vuelo, por las utilidades que of recen al hombre, su sociabilidad, sus costumbres y hábitos, así como por algunas de sus enfermedades más comunes y el modo de curarlas. Solo así, conocidas su morfología y costumbres, podrá intentar su clasificación (72).

En su artículo sobre Australia, los aborígenes, y los canguros aparecían concebidos en un mismo molde unificador. Ahora bien, aún así, pudiéramos entender esta actitud como una mera "naturalización» de lo moral que incluye lo humano.

Todas [las palomas] muestran deseos de vivir en sociedad con sus semejantes, y no parecen tener otra ocupación que la de agradarse mutuamente, reproducirse y cuidar con sumo esmero el fruto que resulta. A pesar de la timidez, carácter peculiar de las palomas, hace ésta frente a quantos intentar robarle el fruto. Eriza sus plumas, forma sonidos de indignación, y no bastando éstos acude á sus armas débiles, que son el pico y las alas, sacudiendo con éstas y picando con aquel al que se acerca, cediendo solamente á fuerzas supcriores. Ni aún entonces se desvía mucho del nido, al qual vuelve inquieta quando le parece que no hay riesgo para acariciar y fomentar su fruto; pero si no lo halla, arrulla con tristeza, búscalo en vano por aquel recinto, y cansada de buscar su robada prenda, después

(71) Véase 23.

(72) Ref. 23, pág. 159. 
de un día de dolor empieza a consolarse con su consorte y renueva los cariños (73).

Le siguen al texto original más adjetivos: arrogancia, fingido desdén, acariciar, gestos expresivos, fingiendo, lubricidad, rubor, valor, temor, amoroso ardor mutuo, celos,... todo un catálogo de epítetos que humanizan a los animales. Un sistema de descripción que considera a su "sociedad" y "familia" como a la nuestra. Incluso se permite discurrir y moralizar sobre la infidelidad y causas de divorcio de las palomas, extrayendo lecciones sobre qué es natural y qué no lo es, o qué enseñanzas morales puede extraer el hombre: "Todo esto (el cortejo y la cópula de las palomas) me parece entrar en el orden de la naturaleza; más no los livianos desvíos que he observado varias veces, viendo que consumado el primer acto cubriendo el macho a la hembra, baxa aquel y sube á su vez la hembra para cubrirlo como si fuera macho. ¡Qué contraste hace la lubricidad de esta acción con el rubor que aparenta el volver la cabeza en la precedente!» (74). Y, con respecto al divorcio, infidelidad, celos y costumbres sexuales: «En lo demás pueden servir de modelo a muchos hombres, porque se asisten mutuamente y se consuelan, y porque parten las cargas anexas a su unión en preparar el nido, en empollar los huevos y alimentar su numerosa prole» (75). Lo natural en este trabajo de Cavanilles cobra, gracias a semejante enfoque una dimensión nueva en él; no sólo el hombre puede ser considerado desde una perspectiva exclusivamente natural sino que los animales pueden ser tratados, en justa reciprocidad, con un criterio moral. La consideración unificada de la naturaleza y la humanidad, característica de la Historia Natural y Moral, permite una auténtica concepción unificada del mundo.

\subsection{Observaciones sobre ... el Reyno de Valencia}

Las Observaciones sobre la Historia Natural, geografía, agricultura, población y frutos del Reyno de Valencia, aparecida en los años 1795 y 1797 (76), constituyen su obra no especializada en botánica más importante. Tanto es así, que Antonio José Cavani-

(73) Ref. 23, pág. 148. El subrayado es mío.

(74) Ref. 23, pág. 149.

(75) Ref. 23, pág. 152.

(76) Véase ref. 17. 
lles es hoy día reconocido como el autor de las Observaciones sobre el Reyno de Valencia. Tal y como anuncia el título, sistemátiza y presenta información actualizada sobre historia natural, geografía, agricultura, población, arte, arqueología y todos a aquellos aspectos relevantes para el conocimiento de la actual Comunidad Valenciana. Para ello se vale del trabajo de campo y de la comprobación personal de los datos recogidos en las observaciones y encuestas en los archivos a su disposición; cuenta, además, con una sólida preparación bibliográfica previa, que no desecha a los clásicos (77). Debido a que durante mi exposición en el Seminario de Historia Natural y Moral mi intervención se limitó al análisis de los Anales de Historia Natural y que esta concluía negando la existencia del modelo histórico natural y moral, he optado ahora por incluir una obra que si se conforma a los dictados del "género». De ahí que lo inclya en último lugar y con un tratamiento diferenciado al resto del artículo. El objetivo de dicha inclusión de última hora no es sólo la consideración de una obra de Historia Natural y moral en España, sino el contraste premeditado de ambas facetas de nuestro personaje con el objetivo de llegar lo más lejos posible en la consideración de su obra para nuestros fines.

Las Observaciones, en toda la obra de Cavanilles, es la única monografía que contiene, como enumeraremos más adelante todos y cada uno de los elementos que a nuestro juicio configuran una Historia Natural y Moral. Ahora bien, si queremos caracterizarle apropiadamente debemos señalar sus tres principales diferencias:

1. No trata una realidad exótica y desconocida para el hombre blanco. Describe y estudia la patria chica (europea) del autor.

2. Carece de una historia civil, eclesiástica o de la evolución socio-cultural tal y como la conceptualizarían los misioneros. No está diseñada, por tanto, para incidir sobre una sociedad pagana en un mundo nuevo, sino para conocer mejor y desarrollar Valencia desde el punto de vista económico y social.

3. Abarca solamente en una proporción muy pequeña la temática de índole moral.

(77) El método de trabajo ya fue explicado anteriormente en el epígrafe titulado "El método botánico". 
Y es a nuestro jucio, una Historia Natural y Moral porque:

A. considera a lo natural y lo humano en una misma categoría o «escala natural».

B. integra lo natural y cultural en un solo campo de estudio y análisis;

C. estructura la obra de modo que el principal elemento limitador sea el espacial que se quiere estudiar;

D. desarrolla todas las áreas de conocimiento material y social del área definida;

E. contiene consideraciones de índole diacrónica cercanas a algunas de las tesis evolucionistas (en particular en su tratamiento de la geología);

F. desarrolla gracias a la capacidad totalizadora del esquema y a su versatilidad, una obra moderna con un diseño utilitario; es decir, está motivada por un afán de actualización y manipulación de la realidad a la que se acerca; $y$,

G. explota y se fundamenta en las relaciones lógicas de los elementos, enfatizando en especial durante el siglo XVIII las conexiones lógicas y causales de índole racional y positiva.

\section{CONCLUSIONES}

Para finalizar deseamos incluir una breve relación de conclusiones que, a modo de parcial recapitulación, recoja algunas de las ideas fundamentales desarrolladas durante este trabajo.

Consideramos la caracterización del epígrafe anterior como un esbozo personal de definición de Historia Natural y Moral.

Los Anales de Historia Natural, en donde se editan los artículos y discursos de Cavanilles, si bien no se utiliza la estructura de la Historia Natural y Moral, sí se valen a menudo de consideraciones procedentes de esta concepción del mundo. Animales y seres humanos son considerados en los Anales y en las Observaciones como miembros de una misma y contínua "escala natural». Integrando, al igual que las Historias Naturales y Morales precedentes, lo natural y lo cultural bajo una misma perspectiva.

Su concepción de la naturaleza, en la que incluye al hombre, parece acercarse al evolucionismo con tesis semejantes a las de Lamarck. Si bien hay que tener en cuenta que en la botánica 
persiste en un enfoque fijista, su tratamiento de la geología muestra abiertamente el cambio y la evolución.

Durante el siglo XVIII, la consideración de los principios de índole evolutiva tenían que circunscribirse al tratamiento de cuestiones de filosofía de la historia, la historia humana y, en cierta medida, la geología. Ya que, una consideración abiertamente evolutiva de la naturaleza u "Obra de Dios» acercaba estas tesis a la herejía de un modo peligroso. Claro está con ésta consideración que no pretendemos insinuar en modo alguno que Cavanilles silenciase planteamientos evolutivos personales más «revolucionarios".

$\mathrm{Ni}$ en el estudio sobre la rabia, ni en el de Australia, ni en el de la historia natural de las palomas parece existir un enfoque claramente caracterizable como Historia Natural y Moral. Sin embargo, en los dos últimos, hay esbozos y elementos pertenecientes a la Historia Natural y Moral, pero la misma naturaleza del tema abordado impide, como puede claramente deducirse de lo arriba expuesto, que estos trabajos adopten plenamente la perspectiva histórico natural y moral. Ya que carecen, a diferencia de las Observaciones sobre el Reyno de Valencia, de un área definida y un interés totalizador bajo un mismo prisma intelectual en el que desarrollar !a extraordinaria potencia y versatilidad de una concepción filosófica integradora y racionalizadora como la propia de la Historia Natural y Moral. 